\title{
Centestato
}

\section{Julius Otto Kaiser para os estudos de Bibliografia e Documentação}

\author{
Rodrigo de Sales \\ Doutor; Universidade Federal de Santa Catarina, Florianópolis, SC, Brasil; \\ rodrigo.sales@ufsc.br
}

\begin{abstract}
Resumo: A Bibliografia e a Documentação se consolidaram cientificamente no decorrer do século XX refletindo, principalmente, o trabalho desenvolvido por Paul Otlet no contexto do Instituto Internacional de Bibliografia. A presente pesquisa procura resgatar o trabalho realizado pelo bibliotecário alemão Julius Otto Kaiser que, ao desenvolver uma forma de indexação especializada, contribuiu para a constituição de um arcabouço teórico-metodológico tanto do ponto de vista da Bibliografia quanto da Documentação. Por ser pouco retratado pela literatura correspondente a essas áreas, o objetivo aqui proposto foi evidenciar os aspectos que podem fazer de Kaiser um referencial teórico importante para as áreas da Bibliografia e da Documentação. Os procedimentos metodológicos foram amparados por uma análise comparativa entre os trabalhos de Kaiser e Otlet, sob a perspectiva pragmática de William James. Os resultados apontam importantes convergências entre Kaiser e Otlet no que se referem à análise de assuntos de documentos e à função desta no universo da documentação. Conclui que a indexação preconizada por Kaiser merece ser estudada como referencial teórico-metodológico para os estudos de Bibliografia e Documentação.
\end{abstract}

Palavras-chave: Indexação sistemática. Julius Otto Kaiser. Bibliografia. Documentação. Paul Otlet.

\section{Introdução}

No contexto dos estudos relativos à Bibliografia e à Documentação, abordadas normalmente como áreas caracterizadas por práticas profissionais e científicas, é possível observar certo predomínio de uma tradição francófona liderada especialmente, no século XX, pelas contribuições de Paul Otlet e Suzzane Briet. Tais contribuições extrapolaram os domínios francófonos e alcançaram dimensões internacionais por meio de estudos como os de Samuel C. Bradford, Jesse Shera e Margaret Egan, e, mais recentemente, por meio dos estudos de Michael Buckland, Ron Day, W. Boyd Rayward, Bernadt Frohmann, José Maria 
Izquierdo Arroyo, Felix Sagredo Fernandes e José Lopez Yepes, para citar alguns.

Em artigo publicado em 1903 (traduzido para o inglês por Rayward em 1990), intitulado “A Ciência da Bibliografia e da Documentação", Paul Otlet discute pela primeira vez a questão da cientificidade da Bibliografia e da Documentação enquanto fazeres distintos. Segundo Rayward (1997), quando Otlet usa pela primeira vez o termo documentação, ele o faz com a finalidade de introduzir um termo mais amplo para o tratamento das fontes de conhecimento, que anteriormente tinha sido associado ao termo bibliografia. No referido artigo, Otlet (1903) definiu que a Bibliografia seria responsável pela organização dos documentos, ao passo que a Documentação seria responsável pela organização das informações dos documentos. Entendemos, provisoriamente, que quando Otlet se refere a uma organização de documentos (objetivo da Bibliografia), ele o faz pensando em uma organização mais genérica, uma organização baseada em assuntos gerais tratados nos documentos. Nesse sentido, a organização das informações contidas nos documentos (objetivo da Documentação) seria uma organização mais especializada, voltada aos conceitos trazidos pelos conteúdos dos documentos.

Dado o fato de que o referido artigo de Otlet é pouco conhecido pela literatura brasileira atinente à Bibliografia e à Documentação, adotamos o mesmo como referência central em nosso estudo para abrir uma discussão a respeito de possíveis distinções ou esclarecimentos relativos aos referidos fazeres científicos. Nesse sentido, Bibliografia e Documentação serão entendidas neste estudo como áreas responsáveis pela organização de documentos e pela organização de informações contidas em documentos, respectivamente.

Tocante aos referenciais teóricos que subsidiam os estudos de Bibliografia e Documentação, consideramos que, historicamente, tais estudos têm deixado de lado as contribuições de um importante bibliotecário do século XX - Julius Otto Kaiser. Nascido em Stuttgart em 1868, falecido em Nova Jersey em 1927, Kaiser desenvolveu um sistema de indexação chamado Sistematic Indexing, cujas contextualizações e explicações foram publicadas em 
dois volumes (1908 e 1911, respectivamente). Embora voltados para a área da indexação, os aspectos trabalhados por Kaiser no contexto de sua indexação sistemática convergem fundamentalmente com alguns aspectos trabalhados por Otlet nos contextos da Bibliografia e da Documentação. Nesse sentido, a presente pesquisa tem por objetivo principal evidenciar os aspectos que fazem, ou que podem fazer, de Julius Kaiser um referencial teórico importante para as áreas de Bibliografia e de Documentação.

Para tanto, alguns objetivos específicos foram definidos para a pesquisa: a) identificar os elementos fundamentais da indexação de Kaiser; b) comparar tais elementos com os aspectos principais da Bibliografia (organização de documentos) e da Documentação (organização de informações de documentos) de Otlet e c) evidenciar as convergências entre as contribuições de Kaiser e de Otlet de modo a apresentar aquele como um referencial teórico relevante para as áreas de Bibliografia e de Documentação.

Do ponto de vista metodológico, a pesquisa se apoiou na perspectiva pragmática de William James, segundo a qual o conhecimento está na trajetória das propostas teóricas, ou melhor, no "caminho" percorrido pelos teóricos para solucionarem suas propostas. Nesse sentido, lançamos mão de uma análise comparativa entre os caminhos percorridos por Kaiser, em sua proposta de indexação, e por Otlet, em sua proposta de Bibliografia e Documentação.

No que se refere à estrutura deste artigo, para além desta seção introdutória, o mesmo está composto pela seção 2, destinada aos aspectos atinentes à indexação de Kaiser; pela seção 3, destinada aos elementos trabalhados por Otlet no contexto da Bibliografia e da Documentação; pela seção 4, que apresenta a análise comparativa e os resultados alcançados pela análise realizada nas propostas de ambos os teóricos; e, por fim, uma seção de conclusões.

\section{A indexação sistemática de Kaiser}

Diferentemente de importantes nomes das áreas da Bibliografia, da Documentação e da Biblioteconomia (no espaço próprio da Organização da Informação), Kaiser não foi um teórico adepto ao universo acadêmico e, ao 
que tudo indica, nem pretendeu o ser um dia. Bibliotecário especialista em unidades de informação de escopos comerciais e industriais, Kaiser, nos últimos anos do século XIX e primeiras décadas do século XX, atuou profissionalmente em instituições como o Philadelphia Commercial Museum (EUA), Commercial Intelligence Bureau (Inglaterra), British Westinghouse Electric \& Manufacturing Co. (Inglaterra), Tariff Comission (Inglaterra) e Vickers (Inglaterra), Nobel Explosives Company, Ardeer Factory (Escócia) e Engineering Societies's Library (EUA). Observamos, assim, que a carreira de Kaiser, embora nascido na Alemanha, deu-se em um contexto geográfico marcado por duas regiões especificamente, Estados Unidos e Reino Unido. Além disso, do ponto de vista temporal, Kaiser exerceu sua profissão e desenvolveu suas contribuições ao universo dos documentos em um período em que se destacaram importantes nomes do trabalho bibliográfico, tais como, Dewey, Cutter, Otlet e, posteriormente, Ranganathan (SALES, 2012; DOUSA, 2013). Trata-se de um recorte espaço-temporal fortemente marcado pelo pragmatismo e pelo desenvolvimentismo de produtos e serviços em unidades de informação.

Nos Estados Unidos e no Brasil, pesquisadores como Thomas M. Dousa e Rodrigo de Sales se dedicaram a resgatar, nos últimos anos, o legado de Kaiser para o arcabouço teórico da organização da informação e do conhecimento. As teses de doutorado de ambos os pesquisadores (SALES, 2012; DOUSA, 2013) trouxeram à tona o pioneirismo de Kaiser para o trabalho de indexação de documentos especializados no mundo dos negócios (comercial e industrial), além de ajudar colocar o bibliotecário alemão no rol dos grandes referenciais teóricos da classificação bibliográfica e da indexação.

A pesquisa aqui comunicada procura mostrar que, ao construir uma forma de indexação sistemática, Kaiser contribuiu também para aspectos fundamentais trabalhados pela Bibliografia e pela Documentação. Conforme visto na introdução deste artigo, Bibliografia e Documentação, segundo Otlet (1903) são respectivamente organização de documentos e organização de informações de documentos. Ao analisarmos a indexação de Kaiser, observamos 
elementos que convergem significativamente com o trabalho do bibliógrafo e do documentalista.

A forma de criação de índices de assuntos de documentos desenvolvida por Kaiser foi publicada em dois volumes de uma coleção denominada The Card System Series, cujo primeiro volume foi publicado em 1908, sob o título The Card System at the Office e o segundo, publicado em 1911, sob o título Systematic Indexing. No primeiro volume, Kaiser contextualiza e caracteriza todo o ambiente de documentação especializada no universo dos negócios, desde os tipos de documentos até o mobiliário e os instrumentos utilizados. No segundo, o autor apresenta em detalhes sua proposta de indexação sistemática. Para os propósitos desta pesquisa, centramos atenção na indexação propriamente dita, ou seja, na obra Systematic Indexing.

A literatura com a qual Kaiser lidava em seu ambiente profissional era uma literatura especializada materializada em documentos especializados, denominada por Kaiser de literatura indexável. No universo da indexação de Kaiser, literatura era entendida como o registro descritivo do que se observa e se raciocina a respeito de algo. O registro daquilo que é observado, raciocinado e descrito é realizado por meio das palavras, que são articuladas de acordo com regras reconhecidas, ou seja, de acordo com uma língua. É por meio desta que, segundo Kaiser (1911), se descreve e se registra, de forma inteligível, o que se pensa sobre determinada coisa. Observamos aqui uma perspectiva aristotélica presente na ótica de Kaiser, ou seja, para se entender as coisas é antes necessário entender o que pode ser dito sobre as coisas. Em termos gerais, literatura, sob esta perspectiva, era entendida como o resultado da observação das coisas e da tradução dessa observação em uma dada língua. Para Kaiser (1911), registros eram representantes de conhecimentos e fornecedores de informações presentes nos documentos das organizações.

Outro traço aristotélico observável na proposta de Kaiser está na forma de identificação de informações veiculadas pelos documentos. Kaiser define, no intuito de proporcionar uma análise metódica de assunto, duas categorias semânticas fundamentais, o concreto e o processo. 
Concretes are only known to us superficially. We perceive their likenesses and differences by comparing them. We are unable to give a complete description of any concrete, no matter how many attempt a description. The proof of this is forthcoming with every new discovery, which forces us to modify sometimes some of our fundamental conceptions of concretes, which in turn leads to modifications in our methods of observing and describing them. Hence whatever we assert is always subject to the proviso: at the present stage of our knowledge. It also emphasises the necessity of taking note of any serious assertion even if contrary to our own ideas. (KAISER, 1911, p. 54)

Ao afirmar que os concretos são conhecidos por nós apenas superficialmente e que somos incapazes de dar uma completa descrição a qualquer concreto, Kaiser já está ressaltando a fundamental importância de sua outra categoria, o processo. "Não podemos dizer o que são os concretos, somos obrigados a dar maior atenção aos seus processos, para o que eles fazem ou o que podemos fazer com eles. Observamos o comportamento deles sob dadas condições e comparamos resultados" (KAISER, 1911, p. 55, tradução nossa).

Dadas as dificuldades encontradas no ato de descrever ideias materializadas na literatura especializada, Kaiser partiu para uma possível compreensão das partes que a compõem e, consequentemente, para a definição das partes que compõem um assunto. Visando à categorização das partes que formam um assunto, propiciando uma delimitação fundamentada do léxico de palavras possíveis de serem utilizadas para descrição, Kaiser, aparentemente, se distanciou do princípio de garantia literária (no qual a base do sistema deve ser exclusivamente o material que está sendo tratado, ao invés de considerações puramente teórica) e simplificou a prática da indexação sintetizando a declaração de assunto (enunciado) em terms commodities (nomes, substantivos) e terms of action (verbos). O assunto propriamente dito, ou seja, a coisa da qual um documento trata é o 'concreto', ao passo que o que é dito a respeito dessa coisa (concreto) é o 'processo'.

para fins de indexação devemos dividir nosso estoque de nomes ou termos entre concretos, processos e países, sendo os concretos os produtos com os quais estamos interessados, processos indicando suas ações, e os países indicando as localidades com as quais os concretos estão conectados (KAISER, 1911, p. 57, tradução nossa grifo nosso). 
Com base nessas três categorias - concreto, processo, lugar - Kaiser desenvolve tanto a análise de assuntos especializados (decomposição dos assuntos em suas partes constituintes) quanto a síntese dos mesmos (recomposição artificial das partes dos assuntos em enunciados prefixados). Para esta última, a síntese, Kaiser (1911) prevê algumas modalidades de ampliações, como informações a respeito de datas, autorias e demais informações não contempladas pelas três categorias fundamentais.

Por exemplo, imaginemos um documento qualquer que trate "dos índices de aumento de $40 \%$ na produção de petróleo na Venezuela nos anos 2000”. Após a análise do assunto do referido documento, a síntese poderia ficar o seguinte:

\section{Enunciado: Petróleo (concreto) \\ Produção (processo) \\ Venezuela (lugar)}

Ampliação: ano 2000; aumento de 40\%

Cada descrição bibliográfica referente a algum documento, conforme exemplo acima, deveria ser registrada em cartões padronizados em tamanhos e cores e os cartões alocados em fichários e móveis preparados para recebê-los. A ordenação desses cartões deveria ser orientada pelos chamados cartões guias que, além de especificarem os assuntos dos registros bibliográficos, poderiam contemplar também referências cruzadas, proporcionando uma rede de remissivas entre assuntos semanticamente relacionados.

A análise e a síntese dos assuntos de documentos especializados eram, portanto, realizadas com base na identificação e no reagrupamento das categorias fundamentais e registradas em cartões padronizados que formavam os índices dos assuntos dos documentos.

Para além da construção dos arranjos conceituais dos termos presentes nos índices de assuntos, Kaiser se preocupou também com o arranjo físico dos documentos, lançando mão de técnicas classificatórias para tal. Como a classificação lida com o mesmo assunto exposto na literatura, a concepção de 
um esquema de classificação e a execução do mesmo contemplariam os mesmos elementos contidos na indexação (nos índices), baseando-se nas categorias fundamentais. O agrupamento tanto dos assuntos quanto dos documentos deveria ser feito gradualmente por semelhança, arranjado com base na ordem atribuída e nomeada pela classificação. Em outras palavras, se a análise da literatura indexável fornecia os assuntos que seriam utilizados na construção do índice, cabia à classificação a determinação da ordem desses assuntos, para fins de localização conceitual e física dos materiais.

Portanto, a classificação dos assuntos no método de Kaiser era uma classificação pautada na própria literatura indexável ${ }^{1}$. Após o indexador analisar a literatura, ou seja, definir os termos concretos, processos e países e determinar a ordem conceitual dos termos, iniciar-se-ia a elaboração sistemática do índice, guiada pela lógica classificatória de semelhanças e diferenças. Com as bases do sistema devidamente estabelecidas, ou seja, com a literatura devidamente analisada e com a classificação formalmente definida, restaria compreender a sistematização da indexação, ou seja, o modus operandi da construção de índices. A operação completa para se elaborar um índice de assuntos era dividida por Kaiser (1911) em duas partes: a) análise das informações com vista à sua respectiva reconstituição e posterior classificação em um plano uniforme aplicável a todas as informações a serem incorporadas no índice e; b) arranjo das informações indexadas de acordo com o plano uniforme estabelecido.

Observa-se que Kaiser se preocupou tanto com a organização dos assuntos dos documentos quanto com a organização dos próprios documentos nas unidades de informação. Tais preocupações contemplam as atividades, como veremos mais adiante, tanto da Documentação quanto da Bibliografia.

\section{A Bibliografia e a Documentação de Otlet}

A sistematização realizada por Otlet no artigo de 1903, publicado no Boletim do Instituto Internacional de Bibliografia (IIB), restringia-se, na fase inicial, ao trabalho bibliográfico, proposta que, posteriormente, avançaria para a enunciação de uma nova ciência, a Documentação. Tal proposta aparece de forma embrionária em seu artigo, uma vez que os postulados dessa nova ciência 
do documento seriam sistematizados e aprofundados no "Tratado de Documentação", publicado por Otlet em 1934. Optamos, no entanto, pelas definições dadas no artigo de 1903 por retratar o dinamismo da articulação de um novo saber/fazer científico e, principalmente, pelo fato de que foi no referido artigo que Otlet propôs uma distinção entre a organização de documentos (Bibliografia) e a organização de informações de documentos (Documentação).

Deste artigo, portanto, valemo-nos tão somente desta distinção entre Bibliografia e Documentação, uma vez que a análise que se segue está voltada ao mais repercutido trabalho realizado por Otlet no âmbito do IIB, o repertório bibliográfico universal, mais tarde publicado como Classificação Decimal Universal (CDU).

Resultado de uma organização da informação efetivamente realizada no âmbito do IIB, o repertório bibliográfico de Otlet (e La Fontaine) tomava por base a quinta edição da Classificação Decimal de Dewey (CDD). Embora se tratasse de um sistema hierárquico de classificação, e de base descritiva, o repertório apresentava maior articulação por meio de dispositivos sintagmáticos, avançando a classificação preconizada por Dewey ao adotar em suas notações sistemas semióticos, que, por sua vez, cumpriam funções distintas de relacionamento entre os assuntos.

Para Dousa (2010) e Sales (2012), Otlet levantou a ideia de que a representação dos conhecimentos veiculados pelos documentos poderia ser realizada não somente pela decomposição de unidades bibliográficas menores (como artigos dentro de periódicos ou capítulos dentro de livros), mas, principalmente, pela análise de unidades de informação menores, tais como os conceitos, os fatos e as evidências encontrados dentro dos textos. As unidades de informação (conceitos e fatos), depois de identificadas, poderiam ser reconfiguradas em um novo arranjo, com o propósito de facilitar a recuperação dos documentos.

Esta concepção de se organizar informação com base em unidades de informação menores, presentes tanto em Otlet quanto em Kaiser, exerceria, segundo Dousa (2010) e Sales e Sales (2018), significativa influência nos trabalhos e teorias que surgiriam posteriormente, para citar alguns: a teoria da 
classificação facetada, que desenvolveria suas diretrizes de classificação com base em facetas; os trabalhos desenvolvidos por documentalistas e bibliotecários especializados (primeira metade do século XX) que, diferentemente dos bibliotecários gerais, os quais classificavam livros com base na totalidade dos conteúdos dos documentos, passaram a classificar informações específicas contidas nos conteúdos, por meio das unidades de informação; a distinção, surgida nas décadas de 1950 e 1960, entre sistemas de recuperação de documentos e sistemas de recuperação baseados em fatos/objetos, os quais passaram a fornecer como respostas às requisições dos usuários as informações contidas nos conteúdos, o que pressuporia, obviamente, uma análise da informação e, mais recentemente, os trabalhos de extrações de unidades de informações de documentos digitais dos sistemas de recuperação da informação surgidos a partir da década de 1990, cujos objetivos assentavam-se nas possibilidades de identificar, recuperar e estruturar unidades menores dentro dos textos digitais.

Para Otlet, conhecimento englobava tudo aquilo que se conhecia a respeito dos objetos do mundo externo ou do próprio pensamento, fossem eles objetos físicos (naturais ou artificiais) ou não físicos (leis, pensamentos, sentimentos etc.). Os elementos primários (principais) desses objetos eram os "fatos" ou "ideias", que, estruturados conceitualmente pelos autores, eram registrados nos documentos, de modo a refletir a visão que cada autor tem a respeito dos fenômenos apresentados e discutidos (DOUSA, 2010).

A função do documentalista era, no discurso otletiano, extrair dos documentos os componentes informativos relevantes (unidades de informações), separando-os do contexto bibliográfico original e registrando-os individualmente, possibilitando que tais registros fossem estabelecidos analiticamente em repertórios enciclopédicos, que, por sua vez, propiciariam e interligação entre unidades de informação e publicações diversas (DOUSA, 2010, SALES, 2012, SALES e SALES, 2018).

Do ponto de vista tecnológico, a proposta otletiana era a adoção do sistema de cartões padronizados. Em princípios do século $\mathrm{XX}$, tal tecnologia era moderna e avançava questões práticas de relacionamento entre documentos e 
seus registros. Na visão de Otlet, um sistema baseado em cartões contidos de transcrições padronizadas de informações de assuntos, alocados fisicamente em fichários, relacionados com mobiliários específicos e organizados conceitualmente por um esquema de classificação, era realmente avançado e eficiente, assim como pensara Kaiser. Vale destacar que, embora contemporâneos, e devido à ausência de citações nas obras dos dois autores, não temos registros que confirmem se Otlet e Kaiser se conheceram ou se tiveram acesso aos trabalhos realizados por um ou por outro.

Nesse tipo de sistema, os cartões funcionam como registros individuais das unidades que representam os documentos. Tais cartões figuram como recursos ideais para registrar o resultado das análises de informações relativas a documentos. Cada cartão deveria servir como o portador de uma só unidade de informação extraída de um documento, estabelecendo a relação um-para-um, que corresponderia à ligação entre cartão e uma das unidades de informação de determinado documento (componente informativo extraído do conteúdo do documento). Otlet chamou esse princípio de princípio monográfico (SALES, 2012). Como diferentes cartões poderiam possuir informações referentes ao mesmo assunto, o sistema de cartões permitia definir distinções de cartões por meio de cores, tamanhos e cartões guias, que possibilitavam "referências cruzadas" de assuntos relacionados. Assim, o índice de cartões representaria tanto os componentes individuais da informação quanto a estrutura em que tal informação estaria reunida (DOUSA, 2010; SALES, 2012).

Nesses termos, Otlet parecia pensar dar conta dos aspectos atinentes à organização das informações contidas nos documentos, ou melhor, ao idealizar a estrutura e o arranjo conceitual do repertório bibliográfico universal, Otlet estaria preocupado em criar um instrumento capaz de organizar informações de documentos e, ao mesmo tempo, com seu recurso notacional complexo, composto por sinais gráficos, números e letras, capaz de organizar os próprios documentos em arranjos físicos.

Observamos, por ora, tanto em Kaiser como em Otlet, o duplo papel de se trabalhar tanto uma organização mais genérica, pautada no próprio documento, como uma organização mais específica, pautada nos elementos 
informativos relacionados aos assuntos dos documentos. Podemos, nesse sentido, especular que Kaiser e Otlet, voluntariamente ou não, pensaram juntos a transição de uma organização de documentos (objetivo da Bibliografia) para uma organização da informação ou do conhecimento (objetivo da Documentação).

\section{Uma comparação pragmática entre Kaiser e Otlet: análise e resultados}

$\mathrm{Na}$ tentativa de tornar evidente o trabalho de Kaiser como uma contribuição relevante aos estudos de Bibliografia e Documentação, propomos uma análise comparativa de seu sistema de indexação com o trabalho realizado por Otlet quando da criação do repertório bibliográfico universal, instrumento fundamental no discurso de Bibliografia e Documentação de Otlet. Mais especificamente, analisamos 'como' Kaiser e Otlet procuraram realizar seus trabalhos de organização de documentos e organização de informação.

Para tanto, respaldamo-nos na perspectiva pragmática de James (2006), para quem,

o método pragmático é, primariamente, um método de assentar disputas metafísicas que, de outro modo, se estenderiam interminavelmente [...] O método pragmático nesses casos é tentar interpretar cada noção traçando as suas consequências práticas respectivas. (JAMES, 2006, p. 44)

Em referência ao pragmatista italiano Giovanni Papini, James (2006) explica o método pragmático por meio da seguinte analogia: imagine-se o corredor de um hotel que liga inúmeros quartos, sendo o corredor o método pragmático e os quartos as teorias. Nos quartos, alguns teóricos definem e desenvolvem suas teorias. Na medida em que eles desejarem um meio prático de sair e retornar aos seus respectivos aposentos, para efetivamente obterem contato com o mundo concreto, é necessário percorrer o corredor do hotel. Nesse sentido, é possível visualizar que o pragmatismo está no meio das teorias, figurando-se como uma ligação das teorias com o mundo externo, caracterizando-se, assim, como "possibilidade de realização", como caminho possível para acessar aos conhecimentos. 
É sob essa perspectiva de pragmatismo enquanto método, enquanto caminho, enquanto "corredor de hotel", que a presente pesquisa lançou olhar sobre os percursos desenvolvidos por Kaiser e por Otlet.

Conforme apresentado nas seções anteriores, tanto Kaiser quanto Otlet desenvolveram meios de se analisar e sintetizar informações relativas a assuntos de documentos por meio de suas partes constitutivas. Enquanto Kaiser optou pela identificação de categorias fundamentais (concretos, processos e lugares), Otlet preferiu a identificação de fatos, conceitos e evidências nos conteúdos dos documentos. No entanto, não foram somente essas as convergências encontradas entre a indexação de Kaiser e o trabalho de Otlet.

Para conduzir nossa análise comparativa, sob a lente do pragmatismo de James (2006), definimos algumas variáveis que nos serviram de parâmetro de comparação entre os trabalhos desenvolvidos por ambos os autores analisados. Tais variáveis foram: a) o que ambos os autores entendiam por conhecimento, uma vez que, em última análise, eram conhecimentos que ambos desejavam extrair dos documentos; b) quais elementos eles utilizaram para a análise dos assuntos dos documentos; c) como eles resolveram a síntese decorrente da análise dos assuntos; d) quais os produtos gerados em decorrência da síntese dos assuntos; e) qual foi a viabilização tecnológica adotada para a concretização de seus sistemas e f) que princípios surgiram em decorrência de seus sistemas.

Após a definição de tais variáveis de análise, partimos para a leitura sistemática da obra Systematic Indexing de Kaiser (1911) e a cotejamos com literatura que subsidiou o presente estudo no que se refere obra de Otlet, mais especificamente: Otlet (1903), Foskett (1973), Shera (1976), Piedade (1983), Rayward (1997), Svenonius (2000), Dousa (2010), Sales (2012, 2014) e Sales e Sales (2018). A leitura sistemática procurou extrair dos citados textos as informações correspondentes às variáveis descritas acima, e obteve como resultados as informações sintetizadas no Quadro 1, abaixo: 
Quadro 1 - Comparação entre Otlet e Kaiser

\section{OTLET}

KAISER

\begin{tabular}{|c|c|}
\hline Conhecimento: & Conhecimento: \\
\hline $\begin{array}{l}\text { Aquilo que se conhece a respeito dos objetos e do } \\
\text { pensamento - registrado nos documentos. }\end{array}$ & $\begin{array}{l}\text { Resultado da observação e do pensamento que se } \\
\text { tem a respeito de algo - registrado em documentos. }\end{array}$ \\
\hline Elementos da análise de assuntos: & Elementos da análise de assuntos: \\
\hline $\begin{array}{l}\text { Unidades de informação menores } \\
\text { (conceitos, fatos, evidências) }\end{array}$ & $\begin{array}{l}\text { Categorias fundamentais } \\
\text { (concretos, processos e lugares) }\end{array}$ \\
\hline Síntese: & Síntese: \\
\hline Notações classificatórias & Enunciados verbais \\
\hline Produto: & Produto: \\
\hline Repertórios bibliográficos & Índices especializados \\
\hline Tecnologia: & Tecnologia: \\
\hline Sistema de cartões padronizados & Sistema de cartões padronizados \\
\hline Princípios: & Princípios: \\
\hline $\begin{array}{l}\text { Princípio monográfico } \\
\text { Referências cruzadas }\end{array}$ & $\begin{array}{l}\text { Referência individual } \\
\text { Redes de remissivas }\end{array}$ \\
\hline
\end{tabular}

Fonte: elaborado pelo autor

Com base no quadro exposto acima, é possível verificar que, embora Otlet e Kaiser tenham adotado signos distintos para comporem suas sínteses (Otlet - notações classificatórias e Kaiser - enunciados verbais), ambos convergiam em todas as demais variáveis analisadas. Tanto Otlet quanto Kaiser lidavam com um conhecimento necessariamente registrado em algum documento. Há que se ressaltar que o conceito de documento de Otlet transcendia a questão do item bibliográfico. Conforme exposto, ambos trabalharam suas dimensões analíticas com base em partes informativas menores contidas nos assuntos dos documentos. Vale destacar que Kaiser, neste quesito, apresentou um caráter mais teórico que Otlet, uma vez que definiu categorias semânticas que serviam como princípios teóricos gerais para conduzir a análise de todo e qualquer assunto. O esclarecimento dado por Kaiser para a questão das categorias parece mais elaborado que a explicação dada por Otlet para definir as unidades menores de informação. Ao passo que Kaiser trata suas categorias 
como princípios teóricos, Otlet aborda suas unidades de informação como partes informativas de conteúdos.

Embora os produtos gerados por ambos os sistemas sejam distintos quanto à forma de representação dos assuntos (notacional e verbal), tanto os repertórios bibliográficos de Otlet quanto os índices especializados de Kaiser cumpriam funções muito semelhantes, separar os conceitos dos assuntos de seus contextos originais (documentos) e rearranjá-los de forma lógica visando à recuperação de informações semanticamente pertinentes. Para isso, ambos adotaram o sistema de cartões padronizados.

Com relação aos princípios decorrentes de ambos os sistemas, a despeito de ganharem nomes distintos, são exatamente iguais - o princípio monográfico de Otlet é percebido no princípio de referência individual de Kaiser, bem como as referências cruzadas previstas por Otlet estão marcadamente presentes nas redes de remissivas de Kaiser.

Diante do exposto e considerando que Otlet, ao discutir a cientificidade da Bibliografia e da Documentação, foi um nome central para a transição de uma organização de documentos para uma organização de informações de documentos, defendemos a ideia de que Kaiser, por ter percorrido trajetória semelhante ao elaborar sua indexação sistemática, tem condições de entrar no rol dos referenciais teóricos da Bibliografia e da Documentação. Entendemos que o método de indexação deste último pode contribuir para a compreensão teórica e para o assentamento histórico de ambos os fazeres científicos.

\section{Conclusões}

Os estudos atinentes à Bibliografia e à Documentação se consolidaram no decorrer do século XX espelhando uma tradição francófona liderada por Otlet. A partir dos anos de 1990, autores como Buckland, Day, Rayward, Frohmann, Izquierdo Arroyo, Fernandes e Lopez Yepes revisitaram tal tradição sob uma perspectiva de associá-la ao domínio da Ciência da Informação. Entretanto, em que pese a construção teórica e a constituição histórica de um fazer voltado a uma organização de informações relativas a documentos, Julius Kaiser teve participação relevante ao conceber um método para construção de índices 
especializados de assuntos, método, este, significativamente semelhante ao elaborado por Otlet no contexto do Instituto Internacional de Bibliografia.

A presente pesquisa, que conclui ser necessário colocar Kaiser como referencial teórico no quadro epistemológico da Bibliografia e da Documentação, mostrou que, do ponto de vista pragmático, Kaiser e Otlet tomaram caminhos convergentes para concretizar suas propostas de organização de informações, tanto no que se refere à análise de assuntos quanto no que se refere à viabilização de seus métodos.

A comparação entre ambos os teóricos permitiu a constatação de que se há, como o afirmou Otlet, uma distinção entre o fazer do bibliógrafo e do documentalista, e se há uma transição de uma organização do documento para uma organização de informações de documentos, Kaiser a ajudou a construir. A nosso ver, a indexação de Kaiser e a bibliografia e a documentação de Otlet guardam elementos de dialogicidade que merecem ser estudados e retratados pela literatura científica.

\section{Referências}

DOUSA, T. M. Facts and frameworks in Paul Otlet's and Julius Otto Kaiser's Theories of knowledge organization. Bulletin of the American Society for Information Science and Technology, [s. l.], v. 36, n. 2, p. 19-25, dez./jan. 2010 .

DOUSA, T. M. Julius Otto Kaiser and his method of systematic indexing: an early indexing system in its historical context. 2013. Dissertation (Doctor of Philosophy in Library and Information Science) - University of Illinois, Urbana-Champaign, 2013.

FOSKETT, A.C. A abordagem temática da informação. Tradução de Antônio Agenor. São Paulo: Briquet de Lemos: Polígono; Brasília: Ed. UnB, 1973.

JAMES, W. Pragmatismo. Tradução de Jorge Caetano da Silva. São Paulo: Martin Claret, 2006.

KAISER, J. O. Systematic indexing. London: Isaac Pitman \& Sons, 1911. (The Card System Series, 2).

KAISER, J. O. The card system at the office. London: Vacher \& Sons, 1908 (The Card System Series, 1). 
OTLET, P. Les sciences bibliographiques et la documentation. Institut International de Bibliographie Bulletin, [s. l.], n. 8, 1903.

OTLET, P. The science of bibliography and documentation. In: RAYWARD, W. B. (ed.). International organization and dissemination of knowledge: selected essays of Paul Otlet. Amsterdam: Elsevier, 1990. p. 71-86.

PIEDADE, M. A. R. Introdução à teoria da classificação. 2. ed. Rio de Janeiro: Interciência, 1983.

RAYWARD, W. B. The origins of Information Science and the International Institute of Bibliography/International federation for Information and Documentation (FID). Journal of the American Society for Information Science, [s. l.] v. 48, n. 4, p.289-300, 1997.

SALES, R. A organização da informação de Julius Kaiser: o nascimento do método analítico-sintético. Saarbrücken, Alemanha: Novas Edições Acadêmicas, 2014, 246 p.

SALES, R. A presença de Kaiser no quadro teórico do tratamento temático da informação. 2012. Tese (Doutorado em Ciência da Informação) Universidade Estadual Paulista, Marília, 2012.

SALES, R.; SALES, F. Kaiser e Otlet: um diálogo pouco lembrado. In: Pereira, A. M.; Kroeff, M. S.; Correa, E. C. D. (org.). As contribuições de Paul Otlet para a Biblioteconomia. Florianópolis: Editora da ACB, 2018. p. 215-238.

SVENONIUS, E. The intellectual foundation of information organization. Cambridge: MIT Press, 2000.

SHERA, J.H. Introduction to Library Science: basic elements of library service. Littleton: Libraries Unlimited Inc., 1976.

\title{
Julius Otto Kaiser for Bibliography and Documentation Studies
}

\begin{abstract}
Bibliography and documentation have been scientifically consolidated throughout the 20th century, mainly reflecting the work developed by Paul Otlet in the context of the International Bibliography Institute. The present research seeks to recover the work carried out by the German librarian Julius Otto Kaiser who, in developing a specialized indexing form, contributed to the constitution of a theoretical-methodological framework both from the point of view of bibliography and documentation. The objective here proposed was to highlight the aspects that can make Kaiser an important theoretical reference for the areas of bibliography and documentation. The methodological
\end{abstract}


procedures were supported by a comparative analysis between the works of Kaiser and Otlet, under the pragmatic perspective of William James. The results point to important convergences between Kaiser and Otlet regarding the subject analysis of documents and their function in the documentation context. It concludes that the Kaiser's indexing deserves to be studied as a theoreticalmethodological reference for bibliography and documentation studies.

Keywords: Systematic indexing. Juluis Otto Kaiser. Bibliography. Documentation. Paul Otlet.

Recebido: 30/04/2019

Aceito: 15/07/2019

\footnotetext{
${ }^{1}$ Para mais detalhes a respeito da classificação e das notações classificatórias no método de Kaiser, ver Kaiser (1911, p. 99 - p. 285).
} 